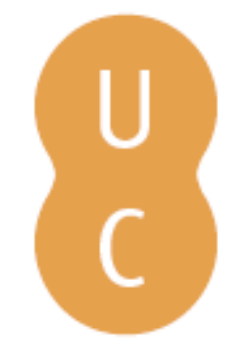

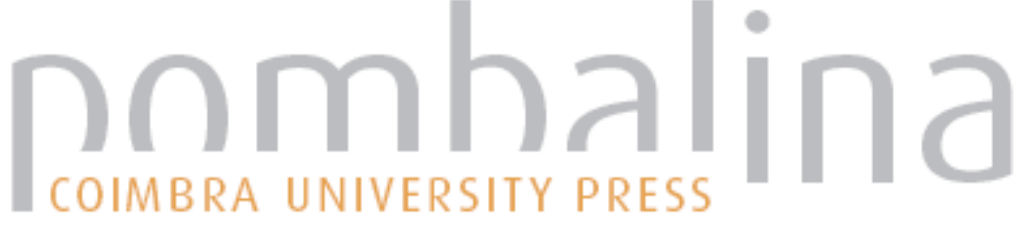

\section{Potenciais contributos das teorias da actividade para os processos de reconhecimento, validação e certificação de adquiridos profissionais}

Autor(es): $\quad$ Moura, Adriano; Alcoforado, Luís

Publicado por: Imprensa da Universidade de Coimbra

URL

persistente: URI:http://hdl.handle.net/10316.2/31241

DOI: $\quad$ DOI:http://dx.doi.org/10.14195/978-989-26-0228-8_8

Accessed : $\quad$ 26-Apr-2023 13:02:12

A navegação consulta e descarregamento dos títulos inseridos nas Bibliotecas Digitais UC Digitalis, UC Pombalina e UC Impactum, pressupõem a aceitação plena e sem reservas dos Termos e Condições de Uso destas Bibliotecas Digitais, disponíveis em https://digitalis.uc.pt/pt-pt/termos.

Conforme exposto nos referidos Termos e Condições de Uso, o descarregamento de títulos de acesso restrito requer uma licença válida de autorização devendo o utilizador aceder ao(s) documento(s) a partir de um endereço de IP da instituição detentora da supramencionada licença.

Ao utilizador é apenas permitido o descarregamento para uso pessoal, pelo que o emprego do(s) título(s) descarregado(s) para outro fim, designadamente comercial, carece de autorização do respetivo autor ou editor da obra.

Na medida em que todas as obras da UC Digitalis se encontram protegidas pelo Código do Direito de Autor e Direitos Conexos e demais legislação aplicável, toda a cópia, parcial ou total, deste documento, nos casos em que é legalmente admitida, deverá conter ou fazer-se acompanhar por este aviso.






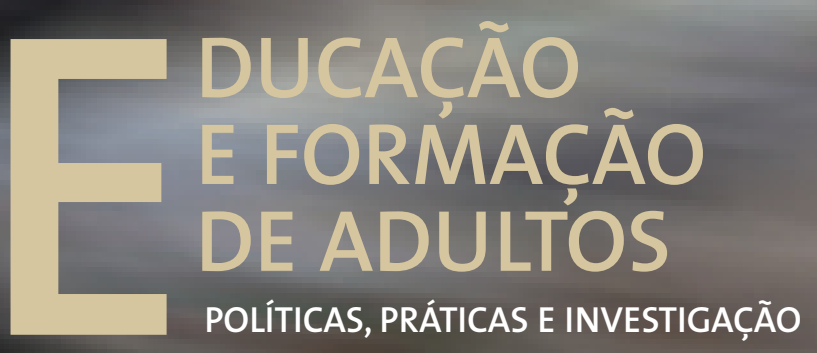

Luís Alcoforado • Joaquim Armando G. Ferreira António Gomes Ferreira • Margarida Pedroso de Lima Cristina Vieira • Albertina L. Oliveira • Sónia Mairos Ferreira 


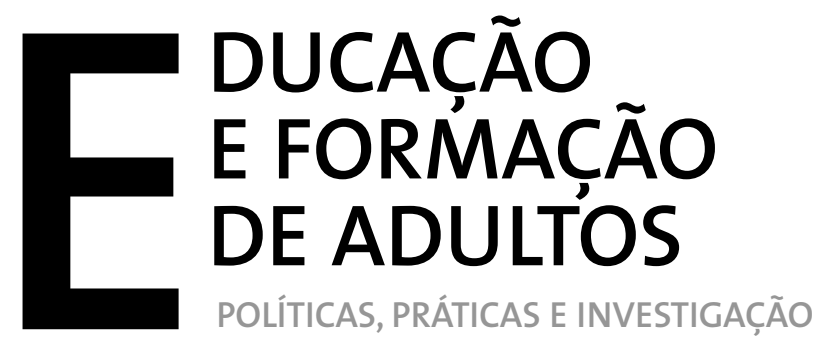

Luís Alcoforado • Joaquim Armando G. Ferreira António Gomes Ferreira - Margarida Pedroso de Lima Cristina Vieira • Albertina L. Oliveira • Sónia Mairos Ferreira 
EDIÇÃo

Imprensa da Universidade de Coimbra

URL: http://www.uc.pt/imprensa_uc

Vendas online: http://www.livrariadaimprensa.com

CONCEPÇÃO GRÁFICA

António Barros

Pré-Impressáo

SerSilito-Empresa Gráfica, Lda

EXECUÇÃo GRÁFICA

SerSilito-Empresa Gráfica, Lda

ISBN

978-989-26-0136-6

DePósito LEgaL

$340309 / 12$ 

POTENCIAIS CONTRIBUTOS DAS TEORIAS DA ACTIVIDADE PARA OS PROCESSOS DE Reconhecimento, Validação e Certificação de adquiridos profissionais

Adriano Moura

Luís Alcoforado

Universidade de Coimbra

\section{Importância e complexidade dos processos de RVCC-PRO}

Ao longo das últimas duas décadas tem-se vindo a sedimentar a necessidade de encontrar os instrumentos legais e as metodologias mais adequadas que nos permitam valorizar socialmente todos os saberes e competências adquiridas nos diversos espaços e tempos das nossas vidas profissionais. Traduzindo um pouco do sentimento geral, Pineau (1997, p. 11) enuncia o princípio fundador desta problemática: "o reconhecimento de adquiridos baseia-se em duas ideias muito simples: há saberes que são adquiridos fora da escola, na vida, na acção, pela experiência, no desenvolvimento de diferentes tarefas [...]; estes saberes, assim adquiridos, procuram o seu reconhecimento na formação ou no emprego, sendo que as necessidades de saberes são tão grandes que nenhum deles pode ser negligenciado, seja qual for a sua origem". Mas, como alerta o mesmo autor, os processos de reconhecimento e validação de adquiridos, nomeadamente os adquiridos profissionais, concentram inúmeras interrogaçóes e controvérsias que apelam, principalmente, à participação e a uma reflexão séria por parte dos profissionais de Educação e Formação de Adultos. Estas interpelaçôes advêm não apenas das questóes sociais que se erguem acerca da credibilidade e validade dos processos de certificação, mas igualmente da confrontação com inúmeras complexidades inerentes à análise de qualquer actividade profissional (Leplat, 1997; Durand, 2009) e da própria aplicaçáo da dimensão prescritiva destes processos.

No nosso país, estamos a assistir ao desenvolvimento e implementação de políticas públicas que, visando a elevação dos níveis de qualificação da população activa, vêm apostando nos processos de reconhecimento pessoal e social dos adquiridos profissionais. Este texto, centrando-se, essencialmente, num questionamento das dimensóes de credibilidade e complexidade dos processos, pretende trazer alguns contributos e reflexóes que possam ajudar a minimizar eventuais efeitos indesejáveis, procurando a amplificação da primeira dimensão e a minimização da segunda.

Neste sentido, a título exemplificativo, evocamos a orientação dos normativos nacionais, segundo a qual a etapa de Reconhecimento se deve iniciar "com o Profissional de RVC, que trabalha com o candidato a identificação das aprendizagens que realizou ao longo da sua vida (...)", cabendo "ao tutor de RVC dar continuidade ao trabalho de enriquecimento e evidenciação de competências mobilizando, para o efeito, os instrumentos de avaliação que integram o "kit de avaliação" (Gomes \& Simóes, 2008, p. 16). Através da realização de uma análise, ao longo de dois processos de RVCC-PRO, tivemos oportunidade de verificar que esta orientação - o facto de estes profissionais não trabalharem em simultâneo com o candidato - pode trazer várias dificuldades à realização do processo de Reconhecimento e Validação de adquiridos. A curto prazo, são as funçôes de acompanhamento dos profissionais que podem ser afectadas, pois por um lado, sem a presença do Profissional de RVC, o Tutor de RVC pode interagir de 
forma implícita com alguns candidatos, fenómeno que não favorece a explicitação de saberes e competências; por outro lado, sem a presença do Tutor de RVC, o Profissional de RVC pode deparar-se com questóes relacionadas com o Referencial da respectiva saída profissional, às quais não consegue dar resposta. A longo prazo, este acompanhamento "desconexo" pode ainda ter como resultado a elaboração de uma história de vida (com o apoio do Profissional de RVC), onde se encontram descritas de forma mais ou menos pormenorizada as experiências profissionais do candidato, sem que estas tenham qualquer ligação com a actividade de validação de saberes e competências, elaborada pelo Tutor de RVC através de fichas de exercícios (de teor pós-formativo) realizadas ao longo de sessóes em grupo (Moura, 2009). Consequentemente, podemos afirmar que existe a possibilidade dos profissionais envolvidos no acompanhamento recorrerem a instrumentos de carácter transmissivo, ao longo da fase de reconhecimento e validação, sem terem como ponto de partida a experiência profissional (história de vida) dos candidatos e, simultaneamente, a possibilidade dos candidatos não demonstrarem, ao longo das sessóes (de reconhecimento e validação) e através da elaboração do seus portefólios, o estabelecimento de uma relação entre a descrição das suas experiências profissionais e os saberes e as competências presentes no Referencial.

No sentido de ultrapassar estes e outros possíveis obstáculos ao desenvolvimento dos processos de RVCC-PRO, examinamos em seguida alguns trabalhos que têm como objecto de estudo a actividade humana, nomeadamente a actividade profissional. A análise, necessariamente breve, que se apresentará das referidas teorias não pretende, no entanto, ser exaustiva em termos de abrangência e profundidade, nem que as respectivas metodologias sejam entendidas como receitas prontas a usar no âmbito destes processos. Trata-se táosomente de fornecer linhas de caracterizaçáo geral e aspectos específicos de desenvolvimento que se consideram essenciais para o despoletar de uma reflexão, nos profissionais envolvidos no desenvolvimento dos processos de RVCC-PRO, acerca das suas actuais práticas e de um eventual enriquecimento das mesmas.

\section{As actuais teorias da actividade profissional}

As teorias que apresentamos em seguida - a "Psico-Fenomenologia", a "Didáctica Profissional", e a "Clínica da Actividade" - foram seleccionadas de acordo com as potencialidades que o seu corpus teórico-metodológico apresenta para dar resposta às seguintes questóes: i) De que forma os intervenientes (Profissional de RVC; Tutor de RVC) devem acompanhar o candidato na explicitação e análise das suas experiências profissionais, de modo a que seja possível verificar se este detém efectivamente os saberes determinados e competências inscritas no Referencial da respectiva saída profissional?; ii) Que relação pode ser estabelecida entre saberes e competências presentes nos referenciais de formação e os saberes e competências desenvolvidos nos meios profissionais?

\subsection{A Psico-Fenomenologia e a Entrevista de Explicitação}

A Psico-Fenomenologia, tal como foi desenvolvida por Vermersch (1999), enquanto disciplina que tem por objecto de estudo a experiência subjectiva do sujeito, baseia-se em dois principais pressupostos teóricos, provenientes da fenomenologia de Husserl e da psico- 
logia do desenvolvimento piagetiana: $i$ ) vivemos largamente dependentes de um modo de consciência que se pode designar de "consciência pré-reflectida". Esta forma de consciência directa, segundo Vermersch, é extremamente útil no dia-a-dia, até para realizar tarefas complexas; ii) no entanto, para podermos descrever o que fazemos, para o conhecermos, falta-nos alcançar a "consciência reflectida", fenómeno que não resulta de uma actividade espontânea ou automática, mas de um verdadeiro trabalho cognitivo.

Partindo destes postulados, e da constatação de que a maioria das técnicas e métodos existentes, para tornar a acção inteligível, apresentam um enorme erro metodológico que conduz a "inventar a realidade do outro em referência à sua própria existência" (Vermersch, 2000, p. 58), este autor concebeu a entrevista de explicitação, a qual se apresenta como um conjunto de técnicas (complexas e não intuitivas) de escuta e questionamento que visam ajudar (individualmente ou em grupo) o sujeito a verbalizar, passo a passo, através dos seus recursos cognitivos, uma acçáo singular tal como ela foi efectivamente realizada (Vermersch, 2000). A entrevista de explicitação visa, então, facilitar esta passagem do implícito do vivido ao explícito da consciência reflectida.

A especificidade desta entrevista consiste no facto de visar a verbalização da acção, tal como ela foi efectivamente realizada, ou seja, a verbalização descritiva do vivido na acçấo, entendida como a sucessão de acçóes elementares que o sujeito executa para atingir um objectivo. Para Vermersch, este tipo de verbalização "descritiva” distingue-se de uma verbalização conceptual e de uma verbalização imaginária. No domínio da descrição do vivido da acção, é necessário ter em conta novas diferenciações - os sistemas de informação satélite da acção. De acordo com Vermersch importa que, no momento da descrição, o sujeito se focalize essencialmente no sistema procedimental, onde se localizam: os saberes práticos, o desenrolar das acçóes elementares, as acções mentais. Consequentemente, a descrição deste sistema permite igualmente inferir as suas intenções e "os saberes efectivamente utilizados na acção" (Vermersch, 2000, p. 49). Para que haja uma descrição do vivido da acção, é portanto essencial que o entrevistador acompanhe o sujeito entrevistado no processo de focalização numa tarefa específica (uma ocorrência particular realizada em determinada circunstância), que permitirá um acesso aos conhecimentos inscritos na acção (singular), para "a partir deste nível de informação básico, ser então possível uma generalização" (Vermersch, 2000, p. 53).

Durante este processo de verbalização do vivido de modo específico e procedimental, a postura do entrevistador deve assentar num misto entre náo-directividade, escuta activa e direccionamento, através de intervençôes dirigidas para o vivido do próprio sujeito. Por seu lado, do entrevistado espera-se que assuma uma posição de palavra "implicada", "incarnada 1", ou seja, no momento em que fala da situação passada, o sujeito deve ter mais presente no seu pensamento a situação específica relatada (a sua memória a longo prazo, auto-biográfica) que o momento presente do relato.

\subsubsection{A operacionalização da Entrevista de Explicitação}

De acordo com Vermersch, antes e ao longo da realização da entrevista, é importante ter em conta uma dimensão relacional, através do estabelecimento de um "contrato de

1 No original, "position de parole incarnée" (...) "pensée qui s'accompagne d'évocation, par opposition à celle qui ne s'en accompagne pas, ou qui ne se base que sur des savoirs détachés de la réalité” (Vermersch, 2000, p. 58). 
comunicação" (explícito e discreto) e através da criação e manutenção de uma comunicação intencional. $\mathrm{O}$ estabelecimento de um contrato de comunicação diz respeito à definição do papel de cada um dos intervenientes - uma relação assimétrica, na qual um questiona e guia e o outro procura verbalizar a sua experiência passada. Este contrato, que pode ser entendido como uma necessidade ética de respeito pelo domínio do pensamento privado do sujeito entrevistado, deve ser formulado no início da entrevista ${ }^{2}$, ou ao longo da entrevista ${ }^{3}$. De acordo com Vermersch para estabelecer um contrato de comunicação, o entrevistador deve privilegiar as formulações directas e positivas ${ }^{4}$; evitar as formulações com induçôes negativas ${ }^{5}$; e evitar um acompanhamento implícito erróneo ${ }^{6}$.

No início da entrevista importa igualmente seleccionar a informação relevante a recolher, tendo em consideração os objectivos individuais e institucionais da mesma.

No desenrolar da entrevista, o entrevistador deve orientar o sujeito para a descrição específica e singular, através de quatro procedimentos básicos: $i$ ) recorrer a um questionamento acerca do vivido nomeando apenas o que já foi referido pelo sujeito; ii) recorrer a expressóes que orientem a atenção do sujeito para a alusão à experiência ${ }^{7}$; iii) evitar questóes de resposta fechada, ou questóes que induzam respostas da ordem do já conceptualizado, nomeadamente pedidos de explicaçóes directas ${ }^{8} ; i v$ ) realizar um questionamento descritivo baseada no advérbio interrogativo de modo "como?".

Em jeito de síntese, podemos referir que todas as técnicas apresentadas visam a criação de obstáculos à verbalização de uma palavra já disponível, já pensada, através de questôes e orientaçóes que guiem o sujeito para uma resposta descritiva.

\subsection{A Didáctica Profissional}

A Didáctica Profissional (Pastré, 1999a; Vergnaud, 1992) pode ser definida como uma disciplina que, partindo da análise de situaçóes concretas de trabalho, procura compreender como os sujeitos relacionam os saberes desenvolvidos na actividade profissional com os saberes teóricos previamente existentes (ou desenvolvidos a partir dos primeiros) e, simultaneamente, construir situaçóes formativas através de simuladores com base em situaçóes-problema. A Didáctica Profissional interessa-se portanto com os factores que fazem do trabalho um contexto de aprendizagem propícia ao desenvolvimento do sujeito. É no cruzamento entre a psicologia do desenvolvimento de Piaget e Vygotsky, e a psicologia ergonómica de tradição francófona (Leplat, 1997) que encontramos as suas principais bases teóricas. Da psicologia ergonómica, a Didáctica Profissional retomou a distinção clássica entre tarefa (aquilo que se deve realizar) e actividade (aquilo que é efectivamente realizado). De acordo com Leplat (1997), existe um hiato entre o trabalho prescrito e

E.g., "Caso esteja de acordo, vamos então dar início à entrevista, na qual vou procurar ajudá-lo a verbalizar...".

E.g., "Concorda que continuemos?"; "Não compreendi totalmente o que referiu, importa-se de repetir?".

4 E.g., "Interessa-me muito saber como realiza essa tarefa. Concorda que lhe faça algumas questóes? Isso pode ajudar a compreender o que você faz. Está de acordo?”.

5 E.g., "Não tenha medo...".

6 E.g., "Fala-me..."; "Conte-me..."; "Explique-me...".

7 E.g., "E quando...”; "Enquanto... ”; “...e continuando"; “No momento em que...”; "Durante... ”; etc.

8 E.g., "Porquê?". 
o trabalho real, pois a actividade ultrapassa sempre a tarefa. Neste sentido, a análise do trabalho deve manter estes dois pólos.

Partindo de uma concepção piagetiana de aprendizagem como um processo de adaptação na e pela prática, e do fenómeno de conceptualização como o procedimento especificamente humano de adaptação às situações, Vergnaud sublinha o postulado da existência de uma dimensão cognitiva em toda a actividade profissional. Neste sentido, o referido autor insiste numa distinção entre "conceitos" construídos com base em sistemas simbólicos, e as conceptualizaçôes que se desenvolvem na própria acção. Estes últimos podem (ou não) estar associados a uma linguagem própria do meio de trabalho, e estar eventualmente associados a conhecimentos teóricos.

Para estudar estas conceptualizaçôes desenvolvidas através da acção e as relaçóes que se estabelecem entre estas e os saberes ditos formais é necessário, de acordo com Vergnaud, analisarmos a interacção dos sujeitos com a "situação" real pois é nessa "interacção que o sujeito "forma e testa as suas representaçôes e concepçóes" (Vergnaud, 1985, p. 245). Neste sentido, o referido autor apresenta o conceito de "esquema" que designa uma forma de organização da actividade. O esquema permite dar conta da dupla qualidade que podemos encontrar na acção eficaz, a estabilidade e a adaptabilidade, organizando a actividade subjectiva numa articulação contida entre sistemas simbólicos e a situação na qual o sujeito age. Trata-se, portanto, de uma organizaçáo invariante que permite criar uma actividade e uma conduta adaptáveis, segundo as características próprias de um conjunto de situaçóes diferenciadas. Neste sentido, o esquema é composto por diversos elementos, nomeadamente, os objectivos, as regras de acção, e os "invariantes operatórios”. Este últimos são considerados o núcleo do esquema, a sua parte verdadeiramente cognitiva. $\mathrm{O}$ "invariante operatório" é portanto um conceito desenvolvido na acção, que pode não estar necessariamente dependente da verbalização ou de conceitos formais. De acordo com Vergnaud, a análise da acção torna-se imprescindível para identificar estas conceptualizaçôes. No entanto, cabe ao investigador inferir a existência de conceitos, em determinada acção do sujeito, para os relacionar com conceitos formais já existentes. Por outras palavras, é a partir dos conceitos já existentes que o investigador consegue identificar as conceptualizaçóes desenvolvidas pelo trabalhador em determinada situação profissional.

Nos recentes desenvolvimentos da Didáctica Profissional, tendo em consideração a falta de conceitos formais estabelecidos nos referenciais para designar certos invariantes que os trabalhadores desenvolvem em determinadas situaçóes de trabalho, Pastré (1999a) parte das construçôes simbólicas desenvolvidas pelos próprios trabalhadores. Não se trata então de relacionar conceitos desenvolvidos na acção com conceitos formais pré-existentes, mas antes fazer com que os primeiros se desenvolvem até alcançarem o estatuto epistemológico dos segundos. Pastré estabelece então a noção de "conceito pragmático", entendido como o elemento central da organização da acção eficaz, pois permite que o profissional faça um diagnóstico de uma situação, e efectue bem a sua actividade, quer isso esteja (ou não) de acordo com a tarefa prescrita/conhecimentos formais. No entanto, este conceito não está apenas no centro da conceptualização realizada pelos trabalhadores. Ele é também o centro da conceptualização para aqueles que concebem a formação. Utilizando os conceitos de Vergnaud podemos dizer que se trata um invariante operatório que está associado a uma linguagem comum utilizada no meio profissional. O "conceito pragmático" apresenta diferentes funçóes na análise da actividade profissional, nomeadamente: ponto de partida para analisar os processos cognitivos realizados pelo sujeito no desempenho da sua acti- 
vidade profissional; alicerce para conceber situaçôes de formação profissional; e base para possíveis desenvolvimentos, através da análise, nomeadamente o alcance de estatuto de conceito científico.

\subsubsection{Métodos e técnicas da Didáctica Profissional}

Tendo em consideração o objecto de reflexão do presente trabalho, importa focalizar os métodos e técnicas utilizadas no âmbito da Didáctica Profissional que permitem analisar os conceitos desenvolvidos através da actividade profissional, designados de "conceitos pragmáticos".

De acordo com esta perspectiva teórica, a análise da actividade profissional divide-se em três etapas principais: a) Análise da dimensão prescritiva do trabalho e dos conceitos teóricos envolvidos, a qual fornece: $i$ ) uma descrição do decurso da acção; ii) um conjunto de regras da acção, ou regras da profissão; iii) uma descrição do conjunto das relaçôes de causalidade entre parâmetros da acção e resultados da situação. De acordo com Pastré não podemos analisar a actividade dos trabalhadores se não possuirmos um conhecimento mínimo da situação e das suas características. Esta fase permite igualmente analisar a situação de modo a identificar os conceitos que são dimensôes centrais da situação; b) Análise da actividade dos sujeitos que permite compreender quais os conceitos centrais que adquirem o estatuto de organizadores da acção, fonte de diferentes estratégias e sentido para os trabalhadores. Os elementos da situação que são utilizados para construir os conceitos pragmáticos (ou a pragmatização de conceitos científicos) apenas podem ser identificados pela análise da actividade. Esta segunda etapa pode ser realizada através da construção de um gerador de situaçóes - problema, ou seja, construção de diversas situaçóes que permitem simular a actividade dos operadores; $c$ ) Realização de entrevistas individuais e colectivas (Debriefing ${ }^{9}$ Individual e Colectivo), onde se opera a conceptualização da acção (com base nas explicaçóes do sujeito), e posterior confrontação com a dimensão prescritiva do trabalho (conceitos formais) e com as explicaçóes do colectivo de trabalho. Por fim, o sujeito regressa à situação-problema (simulação), para ser novamente objecto de análise.

A sequência destas etapas tem como propósito multiplicar os contextos de alternância entre contextualização e descontextualização, ou seja, entre acção e linguagem. Ao contrário do acontece na teoria de Vermersch, os hiatos entre linguagem e acção não são entendidos como defeitos da evocação, mas antes um aspecto de desenvolvimento. Pastré constata mesmo que após a análise (numa segunda passagem pelo simulador) eles prevêem mais e agem no ritmo do processo" (1999b, p. 32). Em síntese para Pastré "é necessário explicar mais para compreender melhor" (1999b, p. 33).

\subsection{A Clínica da Actividade}

Criada por Clot (1999), a Clínica da Actividade pode ser definida como uma abordagem que procura, através da co-análise da actividade profissional, desenvolver o "poder de agir" dos profissionais e simultaneamente melhorar as condiçóes dos meios

9 O Debriefing pode ser entendido como um meio de estruturar o regresso sobre a experiência. Este é geralmente utilizado, por um ou mais sujeitos e um formador/especialista, com o objectivo de analisar diferentes pontos de vista sobre as operaçóes realizadas. 
de trabalho. Trata-se portanto de entender a análise do trabalho como um verdadeiro processo formativo, através da confrontação entre os conceitos desenvolvidos por um colectivo de trabalhadores no seio de um meio profissional, e os conceitos científicos que os investigadores colocam à disposição dos anteriores. Neste sentido, a análise do trabalho deve permitir que a acção profissional seja objecto de pensamento não apenas por parte do investigador, mas fundamentalmente por parte do próprio sujeito (Clot, 2001). De acordo com Clot "a análise do trabalho visa sempre, de qualquer modo, compreender para transformar” (1999, p. 2).

Esta abordagem baseia-se na ergonomia francesa (Wisner, Daniellou), na psicopatologia do trabalho (Le Guillant, Billiard) e, essencialmente, na perspectiva histórico-cultural (Vygotski, Bakhtine), pelo que, de forma coerente com estas bases teóricas, a distinção clássica realizada no âmbito da Didáctica Profissional, entre a "tarefa" (aquilo que deve ser feito) e a "actividade realizada" (aquilo que se faz) (Leplat, 1997) aparece, aqui, desdobrada. Do lado da actividade, e partindo da célebre fórmula de Vygotski segundo a qual "o homem é pleno a cada minuto de possibilidades não realizadas" (2003, p. 76), é acrescentada a noção "real da actividade" (o que não se faz, o que se poderia fazer, o que se gostaria de fazer, o que se fez sem necessidade, etc.). Do lado da tarefa, e partindo da definição de "géneros de discurso"10 introduzida por Bakhtine no âmbito dos estudos acerca da interacçáo, é introduzido o conceito de "género profissional" (um corpo intermediário, um intercalar social, entre a actividade do sujeito e a tarefa, que consiste num conjunto de instrumentos técnicos e de linguagem que permitem que o profissional realize determinada acção de forma eficaz, dentro dos parâmetros aceitáveis de uma determinada organizaçáo de trabalho).

De acordo com a abordagem da Clínica da Actividade as noçốes de "real da actividade" e de "género profissional" possuem um carácter de extrema importância no âmbito da análise da actividade do sujeito, pois elas vão permitir que esta última e o colectivo de trabalhadores se desenvolvam. A análise desenvolve portanto a actividade, nomeadamente ao nível do sentido que os sujeitos atribuem à situação vivenciada. É “o enriquecimento da experiência pelo sentido que ela adquire em cada um dos contextos de análise e de acção que constitui a lei fundamental da dinâmica das actividades" (Clot, 2000, p. 135). A análise da actividade não é portanto apenas uma fase preparatória à formação, mas um verdadeiro processo formativo, pois "quanto mais somos capazes de apreender e relatar aos outros as experiências vividas, mais estas são vividas conscientemente” (Vygotski, 2003, p. 78).

\subsubsection{Métodos e técnicas da Clinica da Actividade}

Para que tal desenvolvimento seja possível, as metodologias utilizadas no âmbito da Clínica da Actividade para analisar a actividade profissional, devem respeitar dois princípios básicos: i) a nutrição da discórdia entre profissionais; ii) as mudanças de contextos e destinatários da verbalização do trabalhador. Com este propósito Clot retoma a entrevista de instruçâo ao sósia e desenvolve a autoconfrontaçâo cruzada.

Partido de uma ideia formulada por Vygotski, segundo a qual "a representação de um sósia é a representação da consciência mais próxima da realidade” (2003, p. 93), Clot retomou a metodologia de Oddone (1981) utilizada nos anos 70 nas fábricas da

${ }^{10}$ De acordo com Bakhtine, "qualquer enunciado considerado isoladamente é, certamente, individual, mas cada esfera de utilizaçáo da língua desenvolve os seus tipos relativamente estáveis de enunciados, aquilo que designamos como género de discurso" (1984, p. 265). 
indústria automóvel: a entrevista de instrução ao sósia. Esta entrevista é iniciada através do seguinte pedido: - "Suponha que eu sou seu sósia - uma pessoa exactamente igual a si do ponto de vista físico - e que amanhã tenho que o substituir no seu trabalho. Quais são as instruções que me deve dar de modo a que ninguém se aperceba da substituição?” (Clot, 2000, p. 258).

No decorrer da entrevista estabelece-se um processo de interacção verbal, entre um trabalhador que, ao assumir o papel de instrutor, procura descrever com máximo pormenor a sua melhor imagem acerca das actividades profissionais; e um investigador que, ao desconhecer (ou ao fingir desconhecer) a actividade profissional em causa, procura questionar constantemente a situaçáo profissional e os modos comportamentais que aí podem ser realizados, ou seja, os modos operacionais da acçáo ("como"). Numa segunda fase, a gravação áudio produzida acerca da entrevista é retomada pelo trabalhador que irá procurar comentá-la por escrito, partindo de um questionamento dos "porquês" da sua actividade (Clot, 1999). Esta metodologia tem portanto como objectivo a criaçáo de obstáculos a uma verbalização acerca da actividade profissional já pensada. Trata-se de desnaturalizar a cadeia operatória, de modo a transformar esta linha recta, traçada pelo instrutor para o sósia, em bifurcaçóes sucessivas.

No âmbito da autoconfrontação cruzada a análise da actividade do sujeito atravessa três etapas: $i$ ) constituição de um grupo de análise e de uma concepção partilhada de situaçóes a serem seleccionadas para análise (fase em que são efectuadas observaçóes no terreno pelos investigadores); ii) realização de filmagens que servirão de base à autoconfrontaçáo "simples" e "cruzada". A primeira consiste na análise dos documentos vídeo por parte do trabalhador e investigador (papel de questionamento da actividade). A segunda - autoconfrontação cruzada - consiste na análise dos documentos vídeo, por parte de dois trabalhadores da mesma área profissional, e do investigador (com o papel de fomentar o diálogo e a discórdia entre os profissionais que se encontram perante a mesma situação); iii) discussão dos resultados da co-análise, entre profissionais e investigador, pelo colectivo de trabalho com o propósito de prolongar os seus efeitos. Esta metodologia tem o propósito de estabelecer "um ciclo entre o que os trabalhadores fazem, o que dizem que fazem, e o que fazem com o que dizem que fazem.

Se, como referimos anteriormente, para Clot é necessário compreender para transformar, através da apresentação destas metodologias percebemos que também é necessário transformar para compreender. A verbalizaçáo acerca da actividade, entendida como uma actividade sobre a outra actividade, encontra-se simultaneamente ligada ao passado e ao contexto actual de verbalização (e os seus destinatários). Deste modo, é possível compreendermos que esta actividade possa ser desenvolvida através da co-análise, e que esta análise seja considerada um instrumento formativo.

\section{Potenciais contributos para os Processo de RVCC-PRO}

Passadas em revista as características essenciais das teorias e algumas das técnicas que delas resultam, resta-nos reflectir sobre os contributos diferenciados que elas podem aportar às práticas em curso. É isso que nos ocupará de seguida. 


\subsection{A Psico-Fenomenologia e a Entrevista de Explicitaçáo}

De acordo com o exposto acerca dos principais conceitos e técnicas da Entrevista de Explicitação, podemos concluir que existe a possibilidade desta ser uma ferramenta importante para o desenvolvimento da fase de Reconhecimento de saberes e competências, por parte do Profissional de RVC e Tutor de RVC. Ao apresentar diversas técnicas que têm como objectivo facilitar a verbalização descritiva da acção, pensamos que esta entrevista se encontra em verdadeira consonância com as metodologias utilizadas ao longo desta fase, nomeadamente a História de Vida e o Balanço de Competências, pois todas têm como ponto de partida a experiência do candidato. Consequentemente, a sua utilização poderá permitir o afastamento da utilização de instrumentos de mediação baseados num modo de trabalho pedagógico transmissivo (Lesne, 1984) e abordar uma importante dimensão ética, que deve estar presente sempre que trabalhamos com a experiência de outra pessoa, através da introdução na noção de "contrato de comunicaçáo". No entanto, a verdadeira vantagem da implementação desta entrevista na etapa do Reconhecimento encontra-se no fornecimento de diversas técnicas de questionamento que, ao visar a descrição procedimental da acção, poderão permitir ao Profissional de RVC e ao Tutor de RVC ultrapassarem obstáculos inerentes à explicitação da dimensão implícita da acção profissional do candidato. Neste sentido, esta colocação da acção em palavras pode ter como consequência a reflexão do candidato acerca dos saberes e competências detidos.

Em síntese, a entrevista de explicitação de Vermersch parece poder contribuir para a reflexão acerca dos modos de acompanhamento dos profissionais envolvidos no processo de RVCC-PRO (Profissional de RVC; Tutor de RVC e Avaliador de RVC), nomeadamente na explicitação e análise das experiências profissionais do candidato. No entanto, tendo em conta que o questionamento deve deixar o sujeito verbalizar somente os seus próprios recursos cognitivos, esta abordagem náo possibilita vislumbrar o estabelecimento de uma relação/confrontação entre os saberes e competências efectivamente evocados pelo candidato e os saberes e competências presentes no Referencial da respectiva saída profissional. Por outras palavras, a actividade de linguagem é entendida como uma actividade em segundo grau, que possui apenas a função de recuperação de uma experiência passada.

\subsection{A Didáctica Profissional}

A abordagem da Didáctica Profissional parece dar continuidade às reflexôes proporcionadas por Vermersch. Se a Psico-Fenomenologia e a entrevista de explicitaçáo contribuem para uma reflexáo acerca da actividade de explicitação de saberes e competências presentes na actividade profissional do candidato, a Didáctica Profissional parece contribuir essencialmente para uma problematização do estabelecimento de uma relação entre aqueles saberes e competências e os saberes e competências presentes no Referencial de âmbito profissional. Entre os diversos conceitos desenvolvidos, por Vergnaud e Pastré, para compreender esta relação entre saberes, importa essencialmente recuperar a noção de "conceito pragmático". No âmbito dos processos de RVCC-PRO, este conceito pode revelar-se importante na medida em que pode ser entendido como $i$ ) ponto de partida para a análise do nível de conceptualização desenvolvido pelo candidato na realização de determinada actividade profissional; ii) suporte para a criaçáo de eventuais situaçóes-problema no âmbito do 
desenvolvimento de exercícios de prática simulada ${ }^{11}$ e iii) base para o estabelecimento de relaçóes entre os saberes e competências verbalizados pelo candidato e os saberes e as competências inscritos no Referencial.

Neste sentido, tendo em conta que no seio desta abordagem a linguagem adquire o estatuto de instrumento de conceptualização, a confrontação entre conceitos inscritos na acção (pragmáticos) e conceitos teóricos pode estar na origem de um desenvolvimento mútuo. Não são apenas os conceitos verbalizados pelo candidato que se podem desenvolver através dos conceitos do Referencial, mas simultaneamente, estes podem ser alvo de aperfeiçoamentos e alteraçóes através das diferentes conceptualizaçóes dos candidatos.

No que concerne às metodologias, não podemos depreender que sejam introduzidas com facilidade nas fases de reconhecimento e validação de competências, pois, para além de possuírem um carácter complexo, apresentam como principal desvantagem o facto de ser o analisador (neste caso, o Profissional de RVC e/ou o Tutor de RVC) a verificar, através da análise da actividade e da linguagem sobre a actividade, a eventual existência de conceitos pragmáticos que poderiam ser relacionados com os conceitos do Referencial. Nesta ordem de ideias, o candidato seria novamente privado de um exercício complexo de associação e confrontação entre os seus próprios saberes e competências e os saberes e competências do Referencial.

Em síntese, importa referir que através da Didáctica Profissional podemos entender os processos de reconhecimento e validaçáo de saberes e competências como verdadeiros processos formativos. Não se trata portanto apenas de descrever a actividade profissional no sentido de esta se tornar num objecto de reflexão por si só, mas antes de procurar desenvolver, simultaneamente, os saberes desenvolvidos na acçáo e os saberes teóricos existentes (ou criados a partir dos primeiros).

\subsection{A Clínica da Actividade}

As reflexôes acerca da análise do trabalho fornecidas pela Clínica da Actividade permitem continuar, e mesmo aprofundar, as reflexōes produzidas pela abordagem anterior. Tal como acontecia no seio daquela, com a Clínica da Actividade é igualmente possível vislumbrar a confrontação e o mútuo desenvolvimento entre saberes e competências do candidato e saberes e competências inscritas no Referencial. Consequentemente, é exequível entender os processos de reconhecimento e validação como processos formativos para os candidatos. No entanto, para que tal seja possível, de acordo com a perspectiva da Clínica da Actividade, é necessário que seja o candidato a realizar o movimento de análise da sua experiência profissional através do Referencial em questão. Por outras palavras, a confrontação entre diferentes conceitos deve ser efectuada pelo candidato, para que daí possam resultar aprendizagens significativas.

Partindo desta perspectiva, podemos conceber que para fomentar esta confrontação entre conceitos, o Profissional de RVC e o Tutor de RVC - ao pertencerem a diferentes géneros profissionais - deveriam acompanhar simultaneamente o candidato, de modo que este último, ao mudar de destinatário de acção, se liberte de uma interacção implícita ou de uma descrição demasiado superficial e já pensada, e assim enriqueça a sua descrição

11 Possibilidade de avaliação ao longo da fase de reconhecimento e validação de competências profissionais. 
através de um acesso ao real da actividade. Para aceder a este real, a abordagem da Clínica da Actividade evoca ainda a necessidade de se alimentar discórdia entre os diversos trabalhadores. Ainda no plano metodológico, entendemos que a entrevista de instrução ao sósia, ao contrário do que acontece com a autoconfrontação cruzada devido ao seu carácter complexo e moroso, pode ser utilizada na fase de Reconhecimento de competências pois, tal como acontecia com a entrevista de explicitação, visa a criação de obstáculos a uma verbalização de uma palavra já disponível, através de questóes e orientaçóes que guiem o sujeito para uma resposta descritiva.

É então no jogo entre diferentes destinatários da verbalização e entre as mudanças de diferentes tipos de linguagem (oral e escrita) com diferentes funções, que parece ser possível vislumbrar a linguagem simultaneamente como ferramenta de análise e como ferramenta de conceptualização desenvolvimento da actividade profissional, através dos conceitos presentes no Referencial.

\section{Consideraçöes finais}

Tivemos como principal objectivo a elaboração de uma reflexão acerca dos processos de RVCC-PRO, através de diferentes e complementares abordagens teórico-metodológicas que têm como objecto de estudo a actividade humana (profissional). Neste sentido, gostaríamos que esta não fosse entendida como uma apresentação de conceitos e métodos de análise que, uma vez transferidos para os processos de reconhecimento e validação de competências profissionais, desembocariam sempre numa facilitação da colocação da actividade profissional em palavras e num desenvolvimento dos saberes e competências do candidato, através do Referencial. Ao invés, esta deve ser compreendida como uma ferramenta que pode vir a ser objecto de reflexão por parte de profissionais e investigadores. Deste modo, sublinhamos alguns pontos-chave que podem ser entendidos como pressupostos dos processos de reconhecimento, validação e certificação de competências profissionais: $i$ ) a importância atribuída à co-análise verbal da actividade profissional, baseada nos modos operacionais da acção, para ultrapassar os obstáculos inerentes à evocação dos aspectos implícitos inerentes a toda a actividade humana (profissional); ii) a importância desta evocação como ponto de partida para a construçáo de uma tomada de consciência, por parte do sujeito, relativa aos saberes e competências implicados na sua actividade profissional e, simultaneamente, para a confrontação por parte do sujeito destes saberes e competências com os saberes e competências presentes no Referencial da respectiva saída profissional.

Resta-nos acrescentar algumas consideraçóes importantes. Em nosso entender, esta confrontação de saberes e competências - âmago de todo o processo de RVCC-PRO - deve resultar em construçóes discursivas, ilustrativas da actividade profissional do candidato, que contenham no seu seio os conceitos presentes no Referencial e as suas significaçóes. Por sua vez, para que estes processos possam culminar em certificaçóes equivalentes, em termos de atribuiçáo de valor social (nomeadamente, no mercado de trabalho) às certificaçóes obtidas pela via formal, estas construçóes discursivas devem ser alvo de uma avaliação rigorosa por parte do Tutor e Avaliador de RVC na fase de Validação. 


\section{Referências Bibliográficas}

Bakhtine (1984). L'esthétique de la création verbale. Paris: Gallimard.

Clot, Y. (1999). La fonction psychologique du travail. Paris: PUF.

Clot, Y. (2000). La formation par l'analyse du travail: pour une troisième voie. In B. Maggi, (Ed.) Manières de penser, manières d'agir en éducation et en formation (pp. 113-156). Paris. PUF.

Clot, Y. (2001). Clinique du travail et action sur soi. In. Baudouin \& Friedrich. Théories de l'action et éducation (pp. 255-278). Genéve: De Boeck.

Durand, M. (2009). Analyse du travail dans une visée de formation: cadres théoriques, méthodes et conceptions. In. J. M. Barbier, et al. Encyclopédie de la formation. Paris: PUF.

Gomes, M \& Simôes, M. (2008). A operacionalização de reconhecimento, validação e certificação de competências profissionais - Guia de Apoio. Lisboa, Agência Nacional para a Qualificação, I.P.

Leplat, J. (1997). Regards sur l'activité en situation de travail. Contribution à la psychologie ergonomique. Paris: PUF

Lesne M. (1984). Trabalho Pedagógico e Formação de Adultos - Elementos de Análise. Lisboa: Fundação Calouste Gulbenkian.

Moura, A. (2009). Do trabalho à linguagem sobre o trabalho: Desafios do processo de Reconhecimento, Validação e Certificação de Competências Profissionais. Tese de Mestrado. Universidade de Coimbra: Faculdade de Psicologia e de Ciências da Educação.

Moura, A. \& Alcoforado, L. (2010). Contributos da Entrevista de Instrução ao Sósia para a Validação de Adquiridos Profissionais. In A. Leite., J. M. Castro. \& J. L. Coimbra. Os novos Profissionais da Educaçâo e Formação para o Trabalho. (pp. 85-94). Porto: IEFP/DN.

Oddone, I. R., Alexandra, B., G. (1981). Redécouvrir l'expérience ouvrière. Vers une autre psychologie du travail? Paris: Editions Sociales.

Pastré, P. (1999a). La conceptualisation dans l'action: bilan et nouvelles perspectives. Education Permanente, 139-2.

Pastré, P. (1999b). Travail et compétences: un point de vue de didacticien. Formation Emploi 67, 109-125.

Pineau, G. (1997). La reconnaissance des acquis: deux idées simples qui posent des problèmes complexes. In G. Pineau, B. Lietard \& M. Chaput. Reconnaître les acquis. Démarches d'exploration personnalisée (pp. 11-20). Paris: L'Harmattan.

Vergnaud, G. (1985). Concepts et schèmes dans une théorie opératoire de la représentation. Psychologie française, 30 (4), 245-252.

Vergnaud, G. (1992). Qu'est-ce que la didactique? En quoi peut-elle intéresser la formation des adultes? Education Permanente, 112.

Vermersch, P. (1999). Pour une psychologie phénoménologique. Psychologie Française 44 (1), 7-18.

Vermersch, P. (2000). L'entretien d'explicitation. ESF Éditeur. Issy-les-Moulineaux.

Vygotski, L. (2003). Le problème de la conscience dans la psychologie du comportement. In Conscience, inconscient, émotions. Paris: La Dispute. 

Série Documentos

Imprensa da Universidade de Coimbra

Coimbra University Press

2011

- U

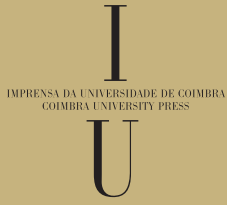

